\title{
Optimizasyon vasıtasıyla Tüp Tipi Akı Anahtarlamalı Doğrusal Jeneratörǜn Vuruntu Kuvveti Azaltımı
}

\author{
${ }^{1}$ Serdal Arslan* \\ ${ }^{1}$ Harran Üniversitesi Birecik Meslek Yüksekokulu Elektrik Programı, Şanlıurfa, Türkiye
}

\section{Özet}

$\mathrm{Bu}$ çalışmada ele alınan akı anahtarlamalı makine yapısal açıdan incelenmiştir. Araç süspansiyon sistemine yönelik tüp tipi akı anahtarlamalı doğrusal makinanın nümerik analizi gerçekleştirilmiştir. Ansys Maxwell'de yeralan genetik algoritma optimizasyon aracı kullanılmıştır. Vuruntu kuvvetini azaltmaya yönelik iki amaç foksiyonu tanımlanmıştır. Ayrıca lazer yer değiştirme sensörü ile hareketli mesafe değişimi incelenmiştir.

Anahtar kelimeler: akı anahtarlama, doğrusal makina, lineer makina, lineer jeneratör, lineer motor

\section{Cogging force reduction of tubular flux-switching permanent magnet linear generator via optimization}

\begin{abstract}
In this study, the flux switching machine is examined in terms of structural aspects. Numerical analysis of tube type flux switched linear machine was performed for vehicle suspension system. Genetic algorithm optimization tool in Ansys Maxwell is used. Two objective functions have been described to reduce the cogging force. In addition, the distance displacement with the laser displacement sensor was investigated.
\end{abstract}

Key words: flux switching, linear machine, linear generator, linear motor

\section{Giriş}

Mevcut fosil yakıt kaynaklarının tükenmesi ve çevreye verdikleri zararlar nedeniyle yeni enerji kaynaklarının kullanımına hatta günlük yaşantımızda enerji kaynaklarının çeşitlenmesine yol açmıştır. Bilindiği gibi fosil yakıtlı kaynakların kullanımının yaygın olduğu sektörlerden biri otomotiv sektörüdür. Son yıllarda yakıt emisyon değerlerine getirilen sınırlılıkların yanı sıra yakıt kaynaklarının tükenmesi nedeniyle otomotiv üreticileri; elektrikli ve hibrit araç tasarımları üzerine çalışmalarını arttırmıştır. Bu çalışmalar sadece araç motoru üzerine olmayıp araçtaki diğer donanımlar üzerine de çalışmalar yapılmaktadır. Araç tasarımcılarının araç sürüş konforu, güvenliğini, verimlilği, araç kütlesi, vb. faktörlerini dikkate almaları elzemdir. Araç sürüş konforu ve sürüş güvenliği; aracın güvenirliliğini doğrudan etkilemektedir. Bu bakımdan araçta yer alan süspansiyon sisteminin belirlenmesi önemli konudur. Özellikle son yıllarda elektromanyetik tip süspansiyon sistemleri dikkat çekmektedir. Gysen vd. [1] hidrolik sisteme nazaran elektromanyetik süspansiyonun avantaj ve dezavantajlarını sıralamıştır:

*Corresponding author: Address: Harran Üniversitesi Birecik Meslek Yüksekokulu Elektrik Programı, Şanlıurfa, Türkiye. E-mail address: serdalarslan@ @arran.edu.tr, Phone: +905469554417 
Avantajları;

1) Artan verimlilik,

2) Gelişmiş dinamik davranış,

3) Kararlılığın iyileştirilmesi,

4) Doğru kuvvet kontrolü,

5) Aktüatörün ikili çalışması,

Dezavantajları ise;

1) Sistem kütlesi ve hacmi az değildir.

2) 12 ila 14 V'lik bir sistem için nispeten yüksek akıma ihtiyaç vardır.

3) Daha yüksek sistem maliyetleri oluşmaktadır.

Doğrusal makinalar; hareketli parça, yapılışlarına ve akı yönüne göre sınıflandırılmaktadır [2,3]. Hareketli parça; çelik, mıknatıs veya sargı olabilir. Yapılarına göre kısa ve uzun stroklu olabilirken manyetik akının yönü enine veya boyuna şeklindedir. Yapılışlarına göre ise hava nüveli veya demir nüveli olarak incelenmektedir. Li ve Pillay [4] hava nüveli doğrusal jeneratörü titreşimli sistem için Flux 2D ile nümerik analizini gerçekleştirmiş ve uygulama sonuçları ile karşılaştırılmıştır. Lu vd. [5] tüp tipi yüzey mıknatıslı doğrusal 5 fazlı makine üzerine çalışmışlar ve nümerik analizlerini de gerçekleştirmişlerdir. Araçlar için yassı tip dört statorlu yapı süspansiyon sistemi de literatürde araştırılmıştır [6]. Pasif süspansiyon sistemleri için genellikle oyuksuz tip doğrusal jeneratörler tercih edilmiştir. $\mathrm{Bu}$ jeneratörlerde; yüksek kuvvet yoğunluğundan dolayı radyal mıknatıslı yapı yerine gömülü mıknatıslı (S-N-N-S dizilimli) yapı tercih edilmektedir. Ebrahimi vd. [7] tüp tipi sürekli mıknatıslı dc makinanın analitik tasarımını gerçekleştirmişlerdir. Wang vd. [8] yarı Halbach mıknatıs dizilimli tüp tipi doğrusal makine (HTDM) ile akı anahtarlamalı tüp tipi makinayı (ATDM) performans ve ağırlık bakımından karşılaştırmışlardır. Çalışmalarında ATDM; düşük hareketli ağırlığında hacimsel güç yoğunluğunun yüksek olduğunu göstermiştir. Ayrıca maliyet ve performans dışında, hareketlinin sağlam yapısı nedeniyle akı anahtarlamalı makina, süspansiyon sisteminde kullanıma aday olarak gösterilebilir. Ancak akı anahtarlamalı ve yarı Halbach tüp tipi jeneratör süspansiyon sistemi için karşılaştırıldığında akı anahtarlamanın daha düşük performans ve maliyetli olduğu görülmüştür [8]. Ayrıca anma akımında HTDM, ATDM'ye nazaran daha fazla elektromanyetik kuvvet üretmesinin yanında daha fazla bakır sargı kullanılamasına rağmen hareketli kütlesi bakımından daha düşüktür [8]. Ancak hareketlide mıknatıs, fırça veya sarg1 olmadığı için akı anahtarlamalı makinalar, basit rotor konfigürasyonu ve mekanik sağlamlık avantajları sağlamasının yanında soğutma zorluğu ve 1sıl kararsızlık sorunu ortadan kaldırılabilir [9]. 12 oluk / 10 kutup ve 12 oluk / 14 kutup yapısındaki ATDM için geleneksel sargıya alternatif sarg1 önerilmiştir. Alternatif sargı yapısının elektromanyetik kuvveti \% $10 \quad-\quad \% \quad 15$ artış sağlamaktadır[10].

\section{Ele Alınan Model ve Özellikleri}

Şekil 1'de görüldüğü üzere modelin hareketli kısımı (sekonder) ferromanyetik malzemeden yapılmış dişli yapıda yekparedir. Primer yine ferromanyetik malzemeden yapılmıştır. Mıknatıslar primer çelik arasına yerleştirilmiştir. Modelin 2B ve 3B görünümü Şekil 1'de verilmiştir: 

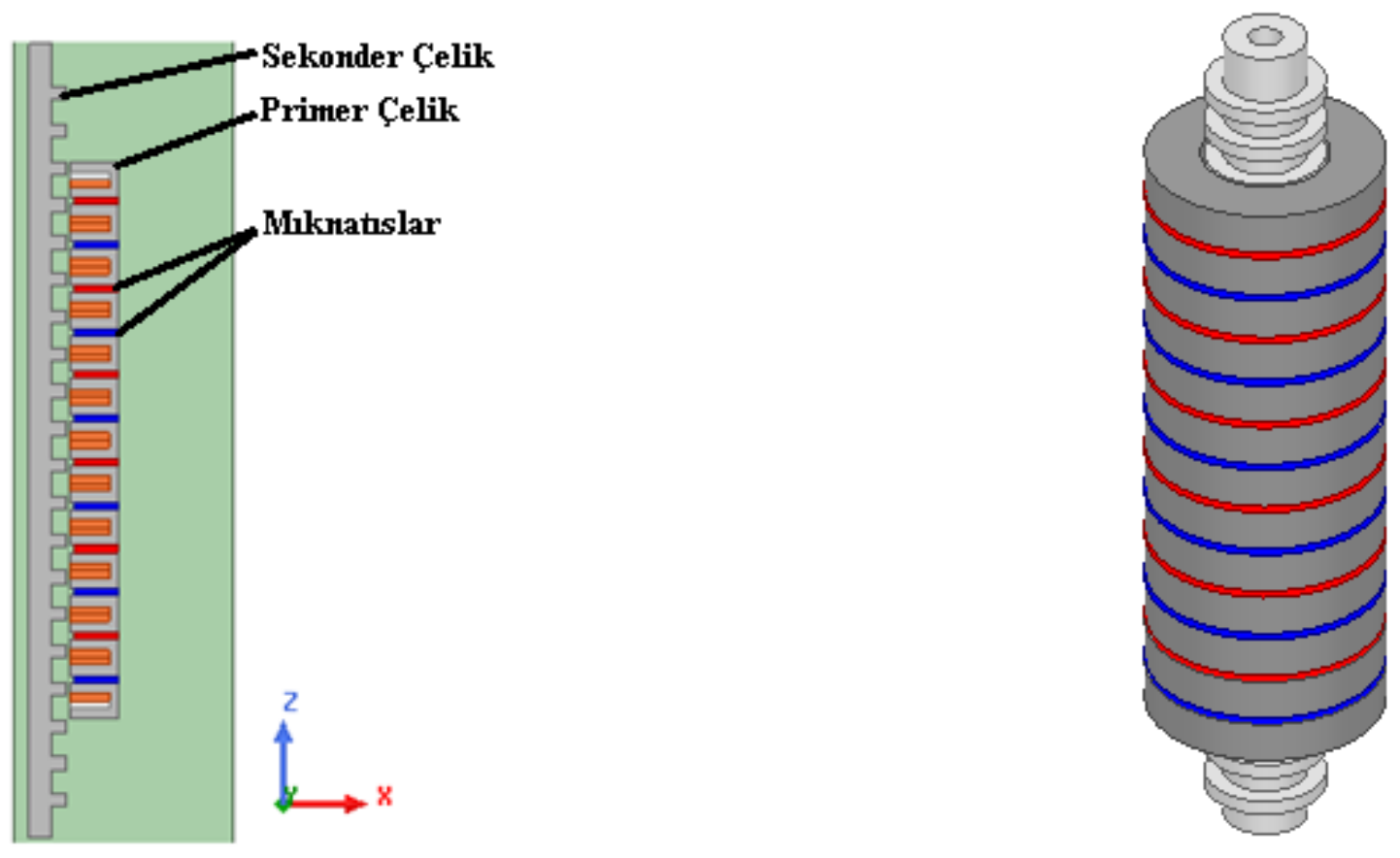

Şekli 1. Model 2B ve 3B görünümü

\section{Genetik Algoritma İle Optimizasyon (GA)}

Stokastik optimizasyon teknikleri içinde yer alan genetik algorima; doğadaki doğal seçim (seleksiyon) temeline dayanmaktadır. Rasgele seçim türü kullanılarak yapılandırılmış bir şekilde uygularlar. Bir jenerasyon oluşturma tekrarlanan bir süreçtir. Her jenerasyonda bazı yeni bireyler (Çocuklar/ Birey Sayısı) oluşturulur ve büyüyen nüfus da nüfusun büyüklüğünü istenilen seviyeye (Sonraki Jenerasyon/ Birey Sayısı) düşüren bir seçime (doğal seleksiyona) katkıda bulunur. Büyük bir gruptan, daha düşük sayıda bireyin bulunduğu bir kümenin oluşturulması gerektiğinde; genetik algoritma birey seçimini ilk kümeden gerçekleştirir. Bu işlem sırasında daha iyi bir uyum sağlayan bireyler (maliyet fonksiyonuna bağlı olarak) tercih edilir. Eğer optimizasyon kurulumu birden fazla hedeften oluşan bir maliyet fonksiyonuna sahipse, her bir hedefe farklı bir ağırlık atanabilmektedir (Eşitlik 1-2). Maliyet hesaplaması sırasında daha yüksek ağırlığa sahip olan hedefe daha fazla önem verilir. Ancak bu çalışmada iki amaç fonksiyonu için eşit alınmıştır. Çeşitli optimizasyon yöntemleri bulunmasına karşın Ansys Maxwell'de tanımlanan optimizasyon yöntemleri (genetik algoritma, ardişik karma değişken nonlineer programlama metodu, Quasi-Newton , vb.) genellikle tercih edilerek optimizasyon başlatılır (Şekil 2). Ayrıca belirlenen değişkenler optimizasyon sürecine dahil edilerek belirlenen kriterler altında optimizasyon süreci gerçekleştirilir. 


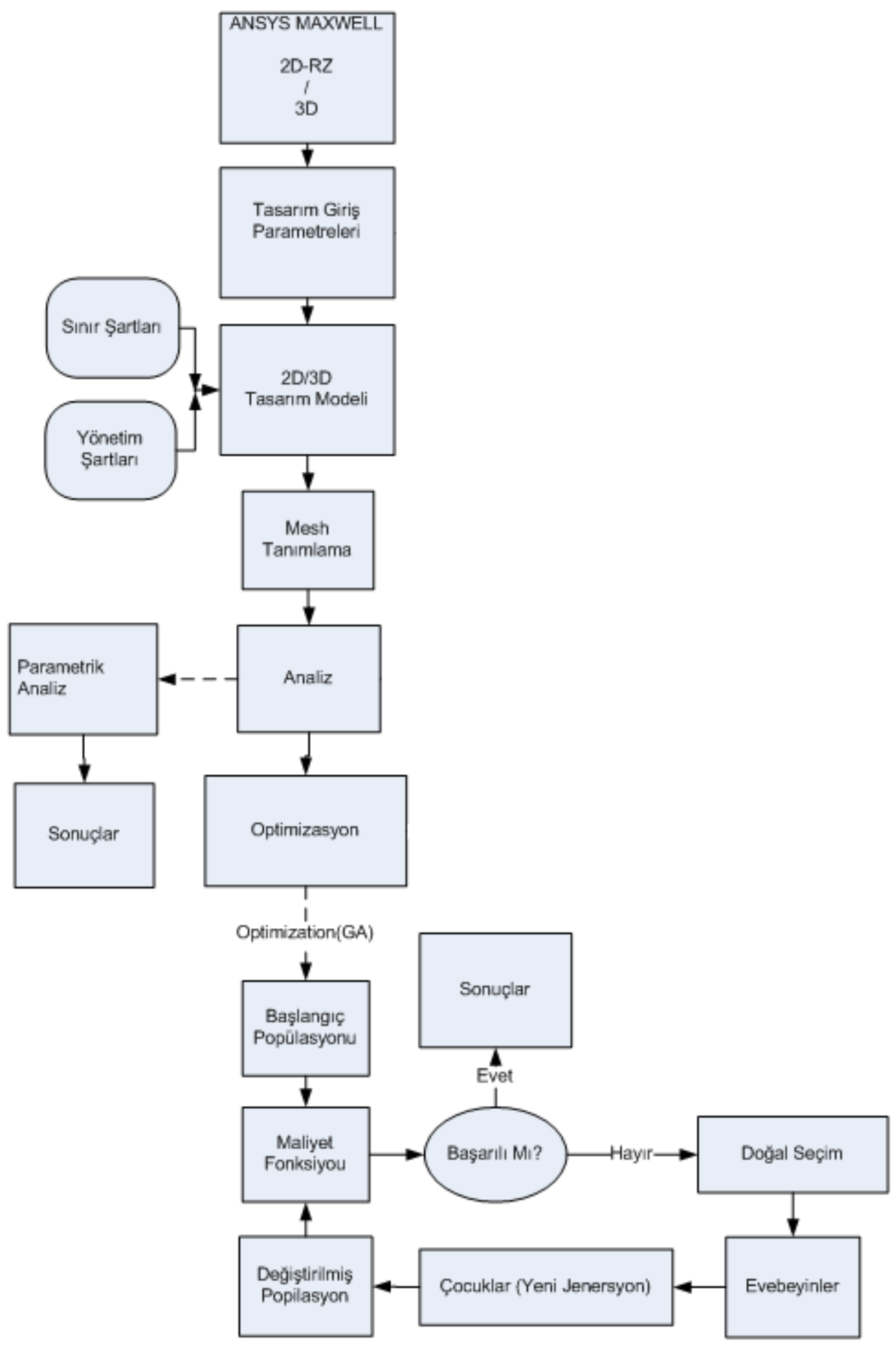

Şekil 2. Ansys Maxwell çözüm akış diyagramı (parametrik, genetik algoritma ile optimizasyon)[11]

Bu değişkenler çok farklı konfigürasyonlarda amaç fonksiyonları içinde tanımlanmıştır. 
Amaç Fonksiyonu $\mathbf{1} \rightarrow \quad r m s(\operatorname{cog} F o r c e)=\mathbf{0} \quad$ Weight $=\mathbf{1}$

$$
\text { Amaç Fonksiyonu } \mathbf{2} \rightarrow \quad p k p k(\operatorname{cog} \text { Force })=\mathbf{0} \quad \text { Weight }=\mathbf{1}
$$

Toplam maliyet fonksiyonu değişimi Şekil 3’te görülmektedir. 37. İterasyonda minimum değere ulaşmıştır.

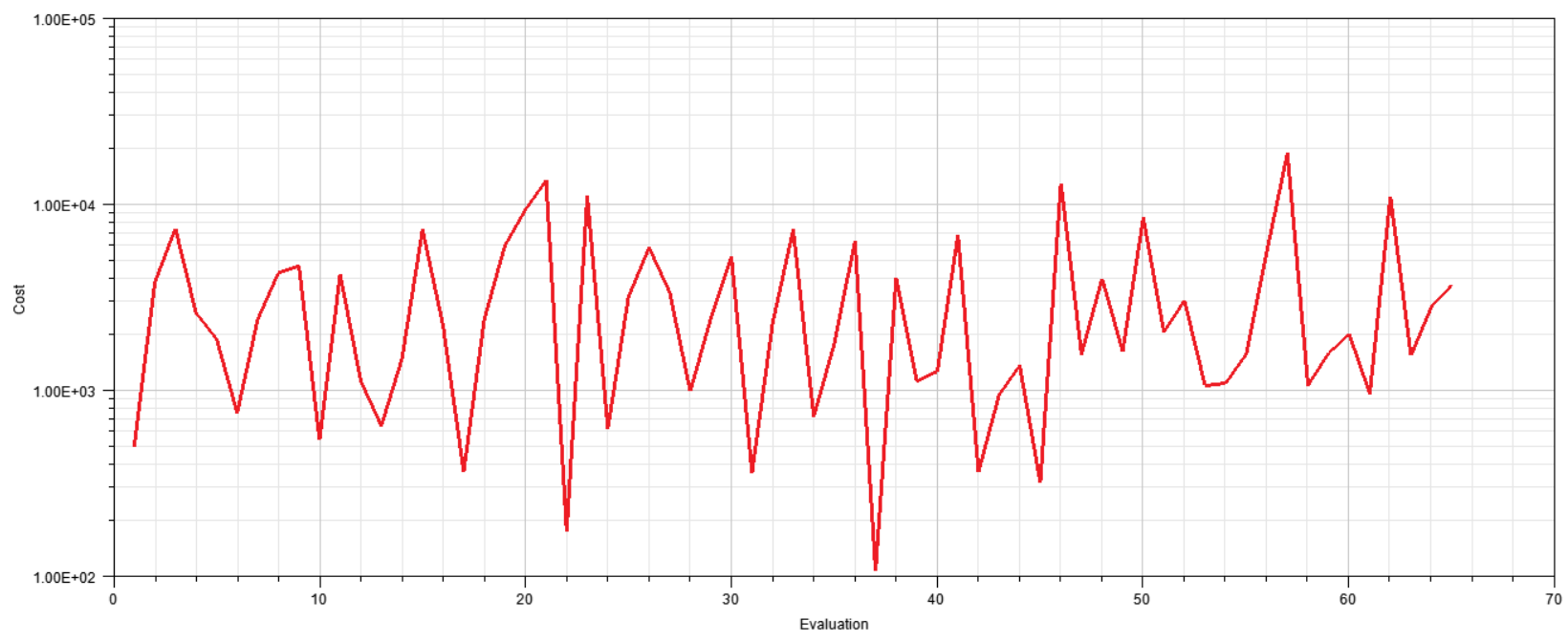

Şekil 3. Toplam maliyet fonksiyonu değişimi

Hareketlideki elektromanyetik kuvvet değişimi Şekil 4'te verilmiştir.

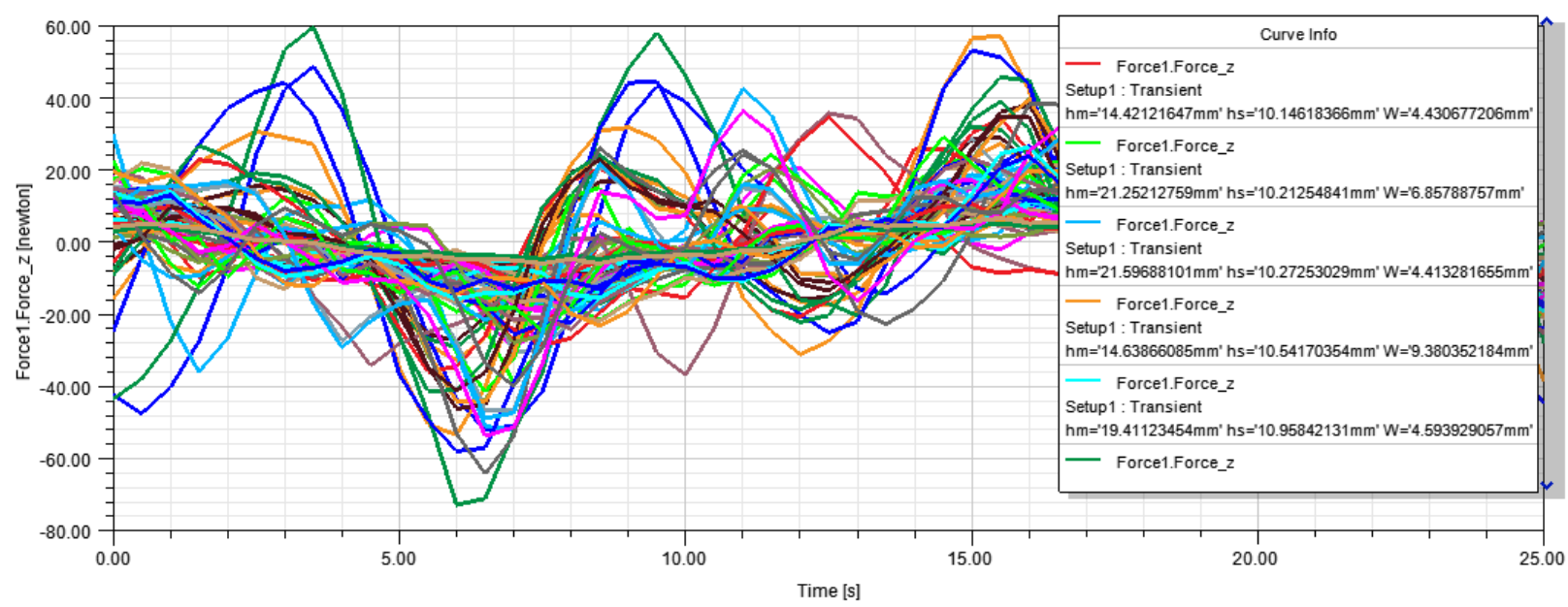

Şekil 4. Vuruntu kuvveti değişimi 
Burada 37. iterasyondaki minimum değerler ayrıca belirtilmiştir. W hareketli diş genişliği, hm mıknatıs yüksekliği ve hs oluk yüksekliği olarak verilmiştir. Hareketli diş genişliği $5 \mathrm{~mm}$, sarg1 yüksekliği $18 \mathrm{~mm}$ olarak alınmıştır. Bu değerler ve piyasada satılan blok mıknatıs değerleri dikkate alınarak mıknatıs yüksekliği $10 \mathrm{~mm} 15 \mathrm{~mm}$ ve $20 \mathrm{~mm}$ olarak paremetrik olarak analizi gerçekleştirilmiştir. Elde edilen verilere göre indüklenen gerilim artmıştır. Mıknatıs yüksekliği 20 mm olarak belirlenmiştir. Burada ilk model ile optimizasyon yapılmış model arasındaki vuruntu kuvveti değişimi Şekil 5 'te verilmiştir.

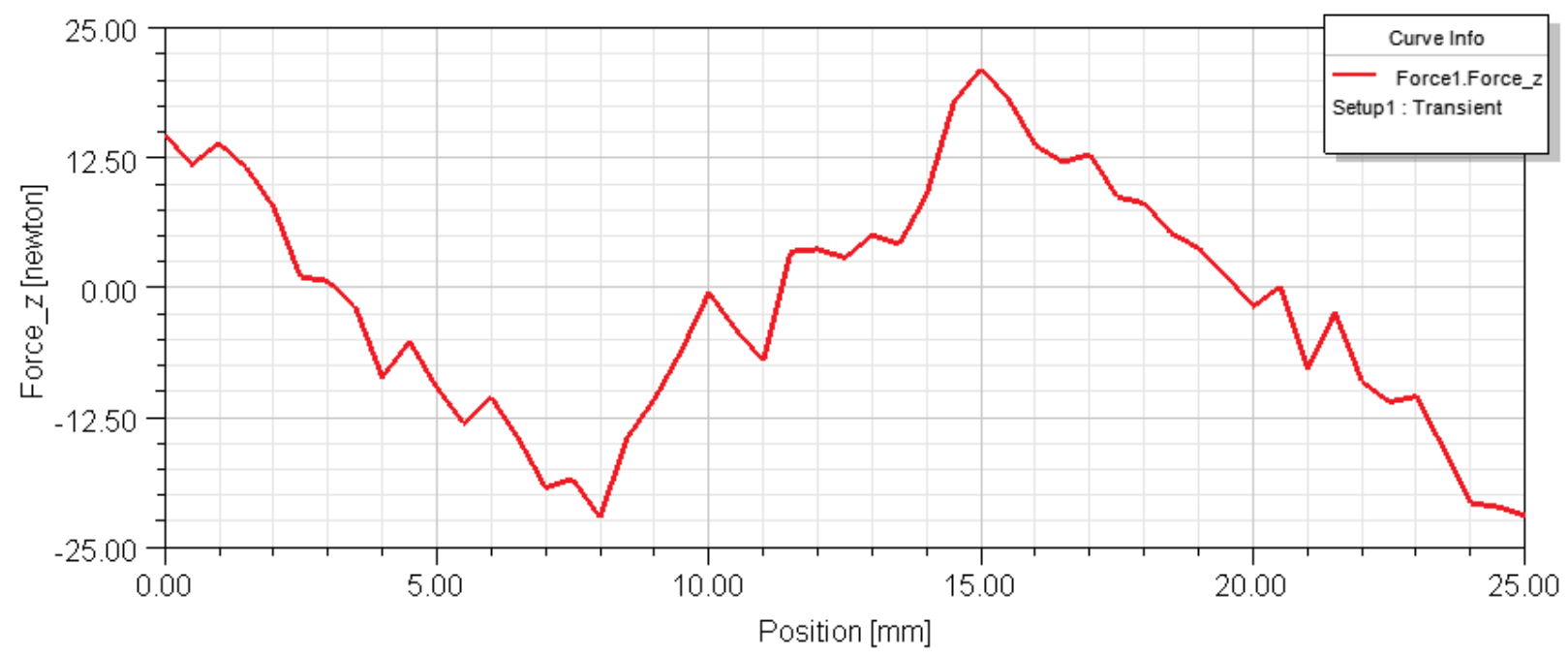

Şekil 5. Vuruntu kuvveti değişimi

Bilindiği üzere krank-biyel sisteminin hareketli mesafesi yarıçap değişimi olmasına karşın gerçek sistemin çalışma durumundaki (örn. motor) harket kabileyetinin incelenmesi bakımından lazer yerdeğiştirme sensörü ile deney gerçekleştirilmiştir (Şekil 6). Asenkron motor sürücü ile kontrol edilmektedir. Motor miline bağlı redüktör üzerinden krank biyel sistemi ile doğrusal makine tahrik edilmiştir. Farklı hareket değişimleri için inceleyebilmek amacıyla krank üzerinde farklı uzunluklarda delikler açılmıştır. Krank yarıçapı 23 mm olarak biyel kolu bağlanmıştır (Şekil 6). $3000 \mathrm{~d} / \mathrm{d}$ senkron hıza sahip asenkron motorun devri redüktör ile $280 \mathrm{~d} / \mathrm{d}$ düşürülmüştür. Mekanik sistemin frekansı yaklaşık 4,66 Hz olarak hesaplanmıştır. Alt kısıma yerleştirilen lazer yerdeğiştirme sensörü (Şekil 6) ile hareketlinin pozisyon değişimi üretici firma arayüzü (NCDT 1420) kullanılarak elde edilmiştir (Şekil 7). Burada yerdeğiştirme sensörü biyel kolunun bağl1 olduğu hareketli tepeden tepeye $46.6161 \mathrm{~mm}$ hareket ettiği görülmüştür. 


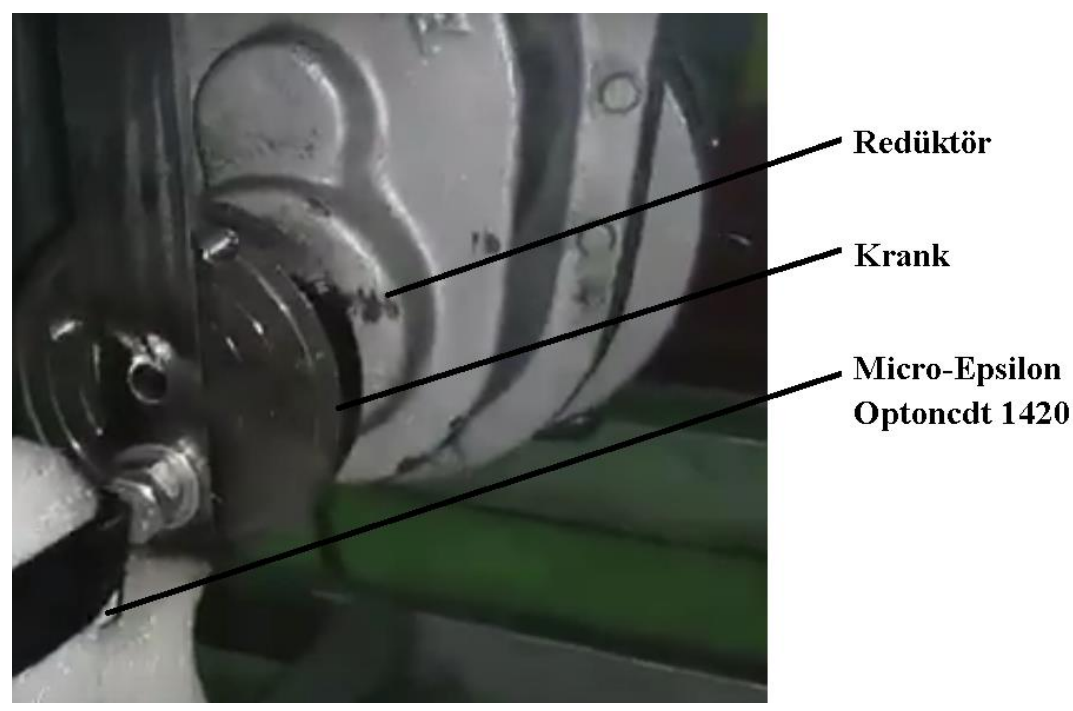

Şekil 6. Lazer yerdeğiştirme sensörü, krank biyel mekanizması ve redüktör

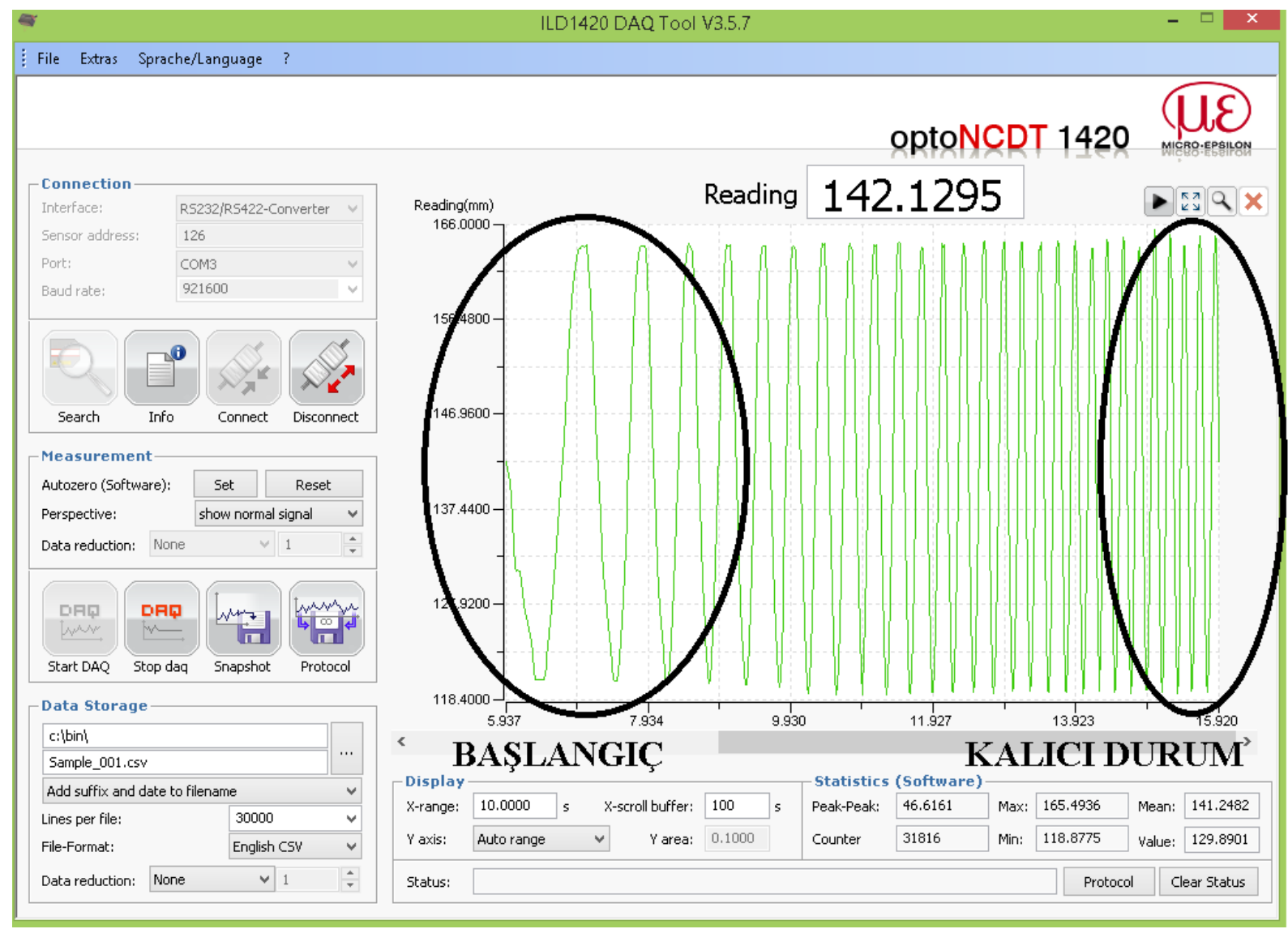

Şekil 7. Lazer yerdeğiş̧tirme sensörü arayüzü üzerinden hareketli pozisyon değişimi 


\section{Sonuç}

Doğrusal makinalarda vuruntu kuvveti dairesel hareketli makinalarda ise vuruntu torkunun değişkenlere yönelik optimum belirlenmesi için sadece vuruntu kuvvetinin etkin ve tepeden tepeye değerini azaltacak amaç fonksiyonu başıı başına yetersiz kalabilir. Bilindiği gibi mıknatıs boyutlarındaki değişim hava aralığındaki akı yoğunluğunu doğrudan etkilemektedir. Bu nedenle makine performansının azalmaması optimizasyondan sonra parametrik analize gerek duymaksızın hava aralığı akı yoğunluğu ifadesini içeren amaç fonksiyonuda eklenebilir. Benzer şekilde diğer sürekli mıknatıslı makinalarada uygulanabilir. İterasyon sayısı arttırılması yada program içinde tanımlı farklı optimizasyon yöntemleri ile vuruntu kuvveti azaltılabilir. Ancak bu yöntemler içerisinde en uygun yöntemi belirlemek kullanıcı tecrübesine bağlıdır.

İleride yapılacak çalışmalar kısaca özetlenirse;

- Akı anahtarlamalı makinada vuruntu kuvvetinin azaltımına yönelik yeni yöntemler uygulanabilir.

- Ele alınan prototip; jeneratör veya motor olarak çalıştırılarak makine karakteristiği incelenebilir.

\section{Teşekkür}

Bu çalışma, Harran Üniversitesi Bilimsel Araştırma Proje Koordinatörlüğü tarafından 18060 proje numarası ile desteklenmiştir. Konu için uygulama videosunaaşağıdaki linkten ulaşabilirsiniz.

https://www.youtube.com/watch?v=2qK_fNsCQpY

\section{KAYNAKLAR}

1. Gysen, B. L., Paulides, J. J., Janssen, J. L., Lomonova, E. A. Active electromagnetic suspension system for improved vehicle dynamics. IEEE Transactions on Vehicular Technology, 2009; 59.3: 1156-1163

2. Arslan, S., Gurdal, O. Polygonal Tubular Linear Permanent Magnet Generator Analysis and Experimental Test. Scientia Iranica, 2019; doi: 10.24200/sci.2019.50094.2739

3. Arslan, S., Overview Of Generating Electricity From Wave Energy Systems And Investigation Of Generator Topologies Used In Archimedes Wave Swing Systems, International Conference on Natural Science and Engineering (ICNASE'16), Kilis, 2016.

4. Li, H., \& Pillay, P. (2011). A methodology to design linear generators for energy conversion of ambient vibrations. IEEE Transactions on Industry Applications, 2011, 47.6: 2445-2452.

5. Lu, Z., Zhou, H., Liu, P., Liu, G., Chen, L. Design and analysis of five-phase fault-tolerant radially magnetized tubular permanent magnet motor for active vehicle suspensions. 19th International Conference on Electrical Machines and Systems (ICEMS), 1-4, 2016. 
6. Ohashi, S. Basic characteristics of the linear synchronous generator using mechanical vibration of the automobile. InElectrical Machines and Systems (ICEMS), 1550-1554, 2010.

7. Ebrahimi, B., Khamesee, M. B., Golnaraghi, M. F. Feasibility study of an electromagnetic shock absorber with position sensing capability. In Industrial Electronics, 34th Annual Conference of IEEE (IECON), 2988-2991, 2008.

8. Wang, J., Wang, W., Atallah, K., \& Howe, D. Comparative studies of linear permanent magnet motor topologies for active vehicle suspension. In Vehicle Power and Propulsion Conference, 1-6, 2008.

9. Kang, M., Ji, J., Liu, G., Zhao, W. A new tubular fault-tolerant permanent-magnet motor for active vehicle suspension. In IECON 2012-38th Annual Conference on IEEE Industrial Electronics Society, 4082-4086, 2012.

10. Wang, J., Wang, W., Atallah, K., Howe, D. Design considerations for tubular fluxswitching permanent magnet machines. IEEE Transactions on Magnetics, 2008; 44.11: 4026-4032.

11. Arslan, S., Oy, S. A. Design and Optimization of Tube Type Interior Permanent Magnets Generator for Free Piston Applications. TEM Journal, 2017; 6.2: 214. 